\title{
Editorial
}

\section{Higher aims and standards, new indexing and submission format}

\author{
Paul Sârbescu ${ }^{1} *$ \& Florin A. Sava ${ }^{1}$ \\ ${ }^{1}$ Department of Psychology, West University of Timişoara, Romania.
}

\begin{abstract}
Address of correspondence: Paul Sârbescu, Department of Psychology, West University of Timişoara, Bld. V. Pârvan nr. 4, Timișoara, 300233, Romania.

E-mail: paul.sarbescu@e-uvt.ro
\end{abstract}

As half of 2019 passed almost like a sparkle already, the first RJAP issue glimmers on the horizon. This editorial unfolds several accomplishments and announces future endeavors for the journal.

"You can't know were you're going until you know were you've been", or so they say. Hence, before we jump to the new additions to the journal, let's take a brief look at our previous volumes. In the past years, RJAP had a lot of diversity - both in terms of article topics and types. Although oraganizational psychology is (probably) the most well represented and consistent area of our journal (e.g. Griep et al., 2015, Veress \& Gavreliuc, 2018), it is far from being the only one. Implicit measures have consistently made their way into our volumes (e.g. Gruber, 2018; Sălăgean, 2017; Şoflău \& Matu, 2016), while transportation psychology has also been represented (e.g. Măirean, 2018). One of the most noticed and cited article from the past few years focused on the national personality profile of Romanians (David et al., 2015). In 2018, bullying was a popular topic: both among primary school children (Ang et al., 2018) and among high school students (DiBlasi, Shin and Dill, 2018). And although the vast majority of published articles are represented by empirical papers, we also published two meta-analyses in the past three years: one on the association between personality and aggressive driving (Iancu, Hogea \& Olteanu, 2016) and the other concerning the efficiency of socio-emotional learning programs (Boncu, Costea \& Minulescu, 2017).

Our previous aims also apply to the future of RJAP. We welcome empirical/methodological papers and metaanalyses from all areas of applied psychology. Literature reviews will only be considered if they provide meaningful ways of advancing applied research. We also wish to increase the number of published papers to +10 per volume. However, as before, quality will always precede quantity and no compromises will be made just for the sake of publishing more papers.

So, what's new about RJAP? Probably the most exciting news concern RJAP's inclusion in PsycINFO and Scopus (very recent). As these new objectives were accomplished, the next stop is Web of Science Emerging
Sources Citation Index. Another novelty concerns a new submission format addition: registered reports.

\section{Introducing Registered Reports as a new submission format}

Starting August 2019, a new submission format will be available for RJAP: registered reports (RRs). How do RRs work: before conducting a study, authors can submit the Introduction and Methods section for peer review. If the study is in line with RJAP's aims and scope, the editors will send the manuscript to reviewers (who will provide feedback on the proposed but not yet conducted study).

After the review process is completed, the authors will receive one of the following decisions:

a) if reviewers consider that the report meets RJAP's standards, the article will be accepted for publication (before the study has been conducted);

b) if the reviewers suggest any modifications, the authors can implement them and resubmit the report;

c) if the reviewers point out critical issues concerning the proposed research (e.g. flawed design, inconsistency between study aims and methods etc.), the report will be rejected.

The initial submission must also include an anticipated timeline for the research to be conducted and an anticipated date for manuscript submission. If the report is accepted for publication (with or without revisions), the authors will sign an agreement committing to submit the proposed research to RJAP and follow the anticipated timeline. The submitted manuscript (after the proposed research was conducted) should contain the same Introduction and Method sections as the initial submission, plus the new Results and Discussion sections. Once submitted, the manuscript will undergo the standard review process, in order to assure that the new sections are adequate as well.

One important feature of RRs is that once the report is accepted, the article will be published regardless of the statistical significance of its findings. That is, of course, assuming the study was conducted exactly in the initially submitted manner. As other editors have noted as well (e.g. 
Greiff \& Allen, 2018), RRs can provide multiple benefits to authors. Probably the main one is that it protects authors from questionable review practices that can contribute to publication bias (i.e. publication decisions based solely on the results). One should also note that this format does not prevent authors to explore their data and present additional exploratory analyses. Pre-registration of a study solely communicates to readers which analyses are exploratory and which are confirmatory. Thus, there is a possible benefit for readers as well: more confidence that the research is reproducible, taken into account that the study was peer-reviewed independent of its results (Nosek \& Lakens, 2014).

Last but not the least, we will strive for increasing the transparency of papers published in RJAP. We will adhere to the Open Science suggested practice of awarding badges for the articles that meet the standards for Open Materials, Open Data, or Pre-registered articles. We will award both the pre-registered articles which were submitted, as well as those who have been registered elsewhere (see more details on this topic at https://cos.io/our-services/open-sciencebadges/).

\section{Closing thoughts}

RJAP is (to the best of our knowledge) the first Romanian journal to introduce RRs submissions and the badging system. We hope that these additions (along with the indexing achievements) will encourage authors to confidently submit their reports and manuscripts for evaluation. Also, we believe that this is a considerable step towards improving research transparency and liability. Lastly, we trust that authors will make use of this new submission format for RJAP.

\section{References}

Ang, C.S., Chong, C.P., Cheong, S.W., Lee, C.Y., Tang, Z., \& Liew, C.Y. (2018). Self-Esteem and tendency of bullying among primary school children. Romanian Journal of Applied Psychology, 20 (1), 11-17.

Boncu, A., Costea, I., \& Minulescu, M. (2017). A metaanalytic study investigating the efficiency of socioemotional learning programs on the development of children and adolescents. Romanian Journal of Applied Psychology, 19 (2), 35-41.

David, D., Iliescu, D., Matu, S., \& Balaszi, R. (2015). The national psychological/personality profile of Romanians. An in depth analysis of the regional national psychological / personality profile of Romanians. Romanian Journal of Applied Psychology, 17 (2), 34-44.

DiBlasi, T., Shin, J.Y., \& Dill, C.A. (2018). Bullying and discrimination experiences among Korean-American junior high school students Romanian Journal of Applied Psychology, 20 (2), 28-36.

Greiff, S., \& Allen, M. S. (2018). EJPA Introduces Registered Reports as New Submission Format. European Journal of Psychological Assessment 34(4), 217-219.

Griep, Y., Baillien, E., Ysebaert, I., \& De Witte, H. (2015). Assessing the experience of unemployment and its associated coping strategies: Grasping context-specific details using Photovoice. Romanian Journal of Applied Psychology, 17(2), 52-62.

Gruber, N. (2018). Green for hope and red for fear? Testing the color effect on the implicit achievement motive. Romanian Journal of Applied Psychology, 20 (1), 1-6.

Iancu, A.E., Hogea, A., \& Olteanu, A.F. (2016). The association between personality and aggressive driving: A meta-analysis Romanian Journal of Applied Psychology, 18 (2), 24-32.

Măirean, C. (2018). The relation between driving cognitions and driving phobia: the moderating role of emotional regulation strategies. Romanian Journal of Applied Psychology, 20 (2), 37-44.

Nosek, B. A., \& Lakens, D. (2014). Registered reports: A method to increase the credibility of published results Social Psychology 45, 137-141.

Salagean, N. (2017). Modifying the IAT to test the relationship between actual implicit self-esteem and depression - a preliminary analysis. Romanian Journal of Applied Psychology, 19 (1), 17-22.

Soflau, R., \& Matu, S. (2016). Explicit and implicit attitudes towards heights: a relationship with acrophobic symptoms and sesnsitivity to cognitive-behavioral treatment. A preliminary report. Romanian Journal of Applied Psychology, 18 (1), 1-7.

Veress, Z.E., \& Gavreliuc, A. (2018). Organizational commitment, organizational justice and work satisfaction: a comprehensive model in a Romanian organizational setting Romanian Journal of Applied Psychology, 20 (2), 60-69. 